Check for updates

Cite this: RSC Adv., 2018, 8, 6341

\title{
Self-powered SBD solar-blind photodetector fabricated on the single crystal of $\beta-\mathrm{Ga}_{2} \mathrm{O}_{3}$
}

\author{
Chao Yang, ${ }^{\text {ab }}$ Hongwei Liang, (D) *b Zhenzhong Zhang, ${ }^{c}$ Xiaochuan Xia, ${ }^{b}$ \\ Pengcheng Tao, ${ }^{a}$ Yuanpeng Chen, ${ }^{\text {ab }}$ HeQiu Zhang, ${ }^{\text {b }}$ Rensheng Shen, ${ }^{b}$ Yingmin Luo ${ }^{b}$ \\ and Guotong Du
}

A Schottky barrier diode (SBD) solar-blind photodetector was fabricated based on the single crystal $\beta$ $\mathrm{Ga}_{2} \mathrm{O}_{3}$. $\mathrm{Cu}$ and $\mathrm{Ti} / \mathrm{Au}$ were deposited on the top and bottom surface of $\mathrm{Ga}_{2} \mathrm{O}_{3}$ as Schottky and ohmic contacts, respectively. The SBD exhibits a higher rectification ratio of up to $5 \times 10^{7}$ at $\pm 2 \mathrm{~V}$. The photoresponse spectra show a maximum responsivity at $241 \mathrm{~nm}$ and a cutoff wavelength of $256 \mathrm{~nm}$. The solar-blind/ultraviolet and solar-blind/visible rejection ratio can reach a high level of up to 200 and 1000 , respectively. It is interesting that the device has a clear response to the solar-blind wavelength at zero bias, which confirms it can be used as a self-powered solar-blind photodetector.

Received 18th January 2018 Accepted 2nd February 2018

DOI: $10.1039 / \mathrm{c} 8 \mathrm{ra00523k}$

rsc.li/rsc-advances the photogenerated carriers within the deep levels, which could cause photocurrent persistence for an extended period (from approximately a few minutes to hours) after the excitation light is shut off, and this phenomenon is called the persistent photoconductivity (PPC) effect. ${ }^{16,18}$ Single crystal material can reduce the defects density to a very low level and increase the device response speed. And eliminating the influences of defects $^{19}$ and narrow band gap heterojunction substrate, ${ }^{20}$ the response range of the single crystal $\mathrm{Ga}_{2} \mathrm{O}_{3}$ photodetector can be limited sharply to solar-blind wavelength. Moreover, the photodetector based on a single crystal can be operated with a low dark current density, which can increase the device sensitivity. Besides, when prospecting the application of avalanche photodetector, single crystal material would be a better choice for the high resistance to avalanche current due to the perfect crystalline quality.

Traditional photodetectors typically require an external bias as the driving force to prevent the recombination of photogenerated carriers. ${ }^{21}$ However, the external power sources limit their independence in application as the size of the power sources always far exceed that of detectors. Nowadays, it is highly desirable for the photodetector to function independently of external power sources. It has been common in the previous reports to call devices of this type "self-powered". ${ }^{18,22,23}$ Selfpowered detectors decrease energy consumption and are more environmentally friendly. Combined with wireless technology, self-powered detectors present greater adaptability and sustainability, even used in unattended hazardous atmosphere or harsh environment. Self-power can be achieved by photovoltaic effect by means of $\mathrm{p}-\mathrm{n}$ junction, heterojunction and Schottky junction. When UV lights incidents into the devices, built-in electric field in these structures can separate photogenerated electron-hole pairs and output the electrical signal. ${ }^{24,25}$
${ }^{a}$ School of Physics, Dalian University of Technology, Dalian 116024, China. E-mail: hwliang@dlut.edu.cn

${ }^{b}$ School of Microelectronics, Dalian University of Technology, Dalian 116024, China ${ }^{c}$ State Key Laboratory of Luminescence and Applications, Changchun Institute of Optics, Fine Mechanics and Physics, Chinese Academy of Sciences, Changchun 130033, China 
In this work, the self-powered $\mathrm{Ga}_{2} \mathrm{O}_{3}$ Schottky barrier diode (SBD) solar-blind photodetector was fabricated with the deposition of $\mathrm{Cu}$ and $\mathrm{Ti} / \mathrm{Au}$ on the top and bottom surfaces of $\mathrm{Ga}_{2} \mathrm{O}_{3}$ single crystal substrate, acting as Schottky and ohmic contact respectively. And the current-voltage $(I-V)$ and photoresponse characteristics of the photodetector were investigated.

\section{Experimental}

The commercial (201)-orient $\beta-\mathrm{Ga}_{2} \mathrm{O}_{3}$ substrate with $680 \mu \mathrm{m}$ thickness was used to fabricate the SBD by cutting along the [010] and [102] orientation into a $5 \times 5 \mathrm{~mm}^{2}$ piece. The unintentional doped $\mathrm{Ga}_{2} \mathrm{O}_{3}$ crystal is n-type with a carrier concentration of about $10^{17} \mathrm{~cm}^{-3}$. The samples were firstly cleaned using methanol ( $5 \mathrm{~min}) /$ acetone $(5 \mathrm{~min}) /$ methanol (5 $\mathrm{min}$ )/deionized water (5 min) successively. Next, the samples were etched in the solution with $\mathrm{H}_{2} \mathrm{SO}_{4}: \mathrm{H}_{2} \mathrm{O}_{2}: \mathrm{H}_{2} \mathrm{O}=4: 1: 1$ for $5 \mathrm{~min}$. Finally, the samples were dipped in $90{ }^{\circ} \mathrm{C}$ deionized water until the temperature cooling down to room temperature. The metal deposition was performed by vacuum thermal evaporation method. Ohmic contact electrode was fabricated firstly with $\mathrm{Ti} / \mathrm{Au}(20 \mathrm{~nm} / 200 \mathrm{~nm})$ deposition on the bottom surface of the $\mathrm{Ga}_{2} \mathrm{O}_{3}$ substrate followed by $500{ }^{\circ} \mathrm{C}$ annealing in nitrogen for $3 \mathrm{~min}$. Then $\mathrm{Cu}(20 \mathrm{~nm})$ was deposited on the top surface of the $\mathrm{Ga}_{2} \mathrm{O}_{3}$ substrate with $150{ }^{\circ} \mathrm{C}$ annealing in nitrogen for $5 \mathrm{~min}$ as the Schottky contact electrode. The schematic structure of the detector is shown in the inset of Fig. 1.

X-ray diffraction (XRD) measurement was carried out to determine crystalline quality using Bruker D8 DISCOVER diffractometer. The $I-V$ characteristics for the SBD were measured using Keithley 4200-SCS semiconductor characterization system. Time-resolved photocurrent response

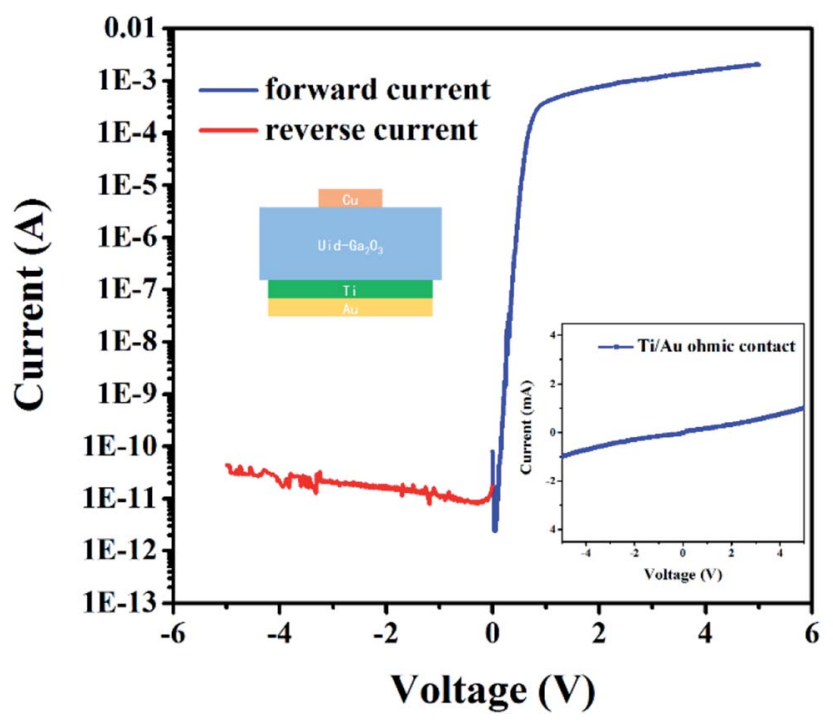

Fig. 1 I-V characteristics of the $\mathrm{Ga}_{2} \mathrm{O}_{3}$ solar-blind photodetector at dark condition. The inset depicts the ohmic contact characterize on the bottom side of the single crystal $\mathrm{Ga}_{2} \mathrm{O}_{3}$.

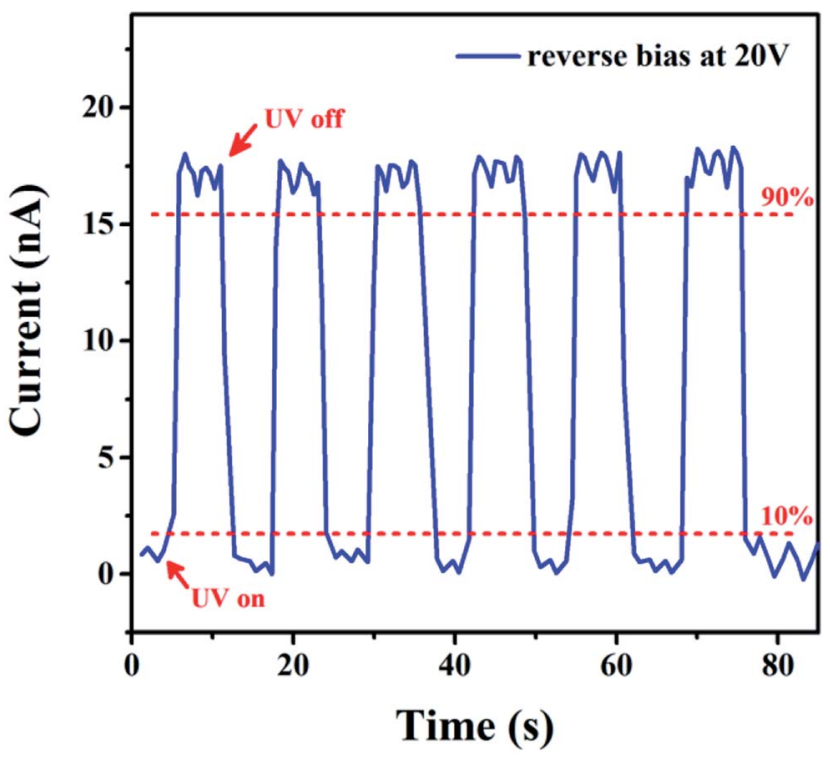

Fig. 2 Time-resolved photocurrent spectrum with the UV light (253 $\mathrm{nm}$ ) of photodetector at -20 voltage.

spectrum was conducted under $254 \mathrm{~nm}$ light with Keithley 4200-SCS semiconductor characterization system. The photoresponse spectra of the photodetectors were measured in a SPEX scanning monochromator employing a $150 \mathrm{~W}$ Xe lamp as the illumination source. The spectrum of the Xe lamp can cover from $200 \mathrm{~nm}$ to over $1000 \mathrm{~nm}$, and the responsivity spectrum was obtained by measuring the photocurrent (calibrated with a standard Si photodiode) under the illumination of the Xe lamp spectrum from $200 \mathrm{~nm}$ to $500 \mathrm{~nm}$ using the scanning monochromator.

\section{Results and discussion}

XRD rocking curve measurement was carried out to determine the crystalline quality of the single crystal $\mathrm{Ga}_{2} \mathrm{O}_{3}$. The full width at half maximum (FWHM) values of ( $\overline{6} 03)$ diffraction peak is 42.2 arcsec (figure not shown here), which confirms good crystalline quality. The $I-V$ characteristics of the photodetector were obtained at dark condition, as shown in Fig. 1. Linear characteristic for the bottom electrode is shown in the inset, which indicates ohmic contacts between $\mathrm{Ga}_{2} \mathrm{O}_{3}$ and $\mathrm{Ti} / \mathrm{Au}$ electrode. In Fig. 1, the forward current is linear in the semilogarithmic scale at low forward bias voltages and deviates from linearity due to the effect of series resistance $R_{\mathrm{s}}$. The reverse current increases slightly, which is probably caused by barrier height inhomogeneities. ${ }^{26}$ The forward current can reach above milliamp order of magnitude and the reverse current is about sub-nanoamp order of magnitude. The SBD exhibits a higher rectification ratio at $\pm 2 \mathrm{~V}$ up to $5 \times 10^{7}$. Assuming that thermionic emission is the dominant current transport mechanism in the SBD, and taking into account the effect of series resistance $R_{\mathrm{s}}$, the diode equations can be written as eqn (1): ${ }^{27-29}$ 


$$
\begin{aligned}
I & =I_{\mathrm{s}} \exp \left(\frac{q\left(V-I R_{\mathrm{s}}\right)}{n K T}\right) \\
& =A^{* *} T^{2} \exp \left(-\frac{q \phi_{\mathrm{b}}}{k T}\right) \exp \left(\frac{q\left(V-I R_{\mathrm{s}}\right)}{n K T}\right)
\end{aligned}
$$

where $I$ is current, $I_{\mathrm{s}}$ is saturation current density, $V$ is applied forward bias voltage, $K$ is Boltzmann constant, $q$ is elementary charge, $n$ is ideality factor, $A^{* *}$ is effective Richardson constant, $\phi_{\mathrm{b}}$ is the barrier height and $T$ is temperature. The effective Richardson constant $A^{* *}$ is calculated to be $41.04 \mathrm{~A} \mathrm{~cm}^{-2} \mathrm{~K}^{-2}$ at room temperature, ${ }^{30}$ using electron effective mass $m^{*}=0.342 m_{0},{ }^{31}$ and free electron Richardson constant $A^{*}=120 \mathrm{~A} \mathrm{~cm}^{-2} \mathrm{~K}^{-2}$. Fitting this model to the linear range of the semi-log plot of $I$ versus $V$, values $\phi_{\mathrm{b}}$ is $0.95802 \mathrm{eV}$ and $n$ is 1.47378 at room temperature. The results are very close to the $\mathrm{Cu} / \mathrm{Ga}_{2} \mathrm{O}_{3}$ Schottky diode based on $\mathrm{Ga}_{2} \mathrm{O}_{3}$ thin film. ${ }^{26}$

The response speed is an important parameter for photodetector, which can be used to evaluate the detection performance to the fast-varying signal. Time-resolved photocurrent response spectrum was measured with on/off switching of $254 \mathrm{~nm}$ light under a working bias of $-20 \mathrm{~V}$, as shown in Fig. 2 . The $10-90 \%$ rise time is estimated to be $0.729 \mathrm{~s}$ and $90-10 \%$ decay time to be $1.209 \mathrm{~s}$ and no long time PPC effect is observed due to the high crystalline quality. This PPC phenomenon is generally found in the $\mathrm{Ga}_{2} \mathrm{O}_{3}$ thin film and nanostructure photodetectors. $^{32,33}$ The on and off state current for six cycles remain the same level, which indicates the high reversibility and high reproducibility of the $\mathrm{Ga}_{2} \mathrm{O}_{3}$ solar-blind photodetector.

Fig. 3(a) is the photoresponse spectra under different reverse voltages up to $35 \mathrm{~V}$. The responsivity at peaks increases obviously at low bias range, while it increases slowly at high bias range due to the recombination as the photogenerated carriers transport through the single crystal. The responsivity of the photodetector can be calculated by eqn (2): ${ }^{34}$

$$
R=\frac{I_{\text {photo }}-I_{\text {dark }}}{S \times P}
$$

where $R$ is the responsivity of the photodetector, $I_{\text {photo }}$ is the photo current, $I_{\text {dark }}$ is the dark current, $S$ is the effective

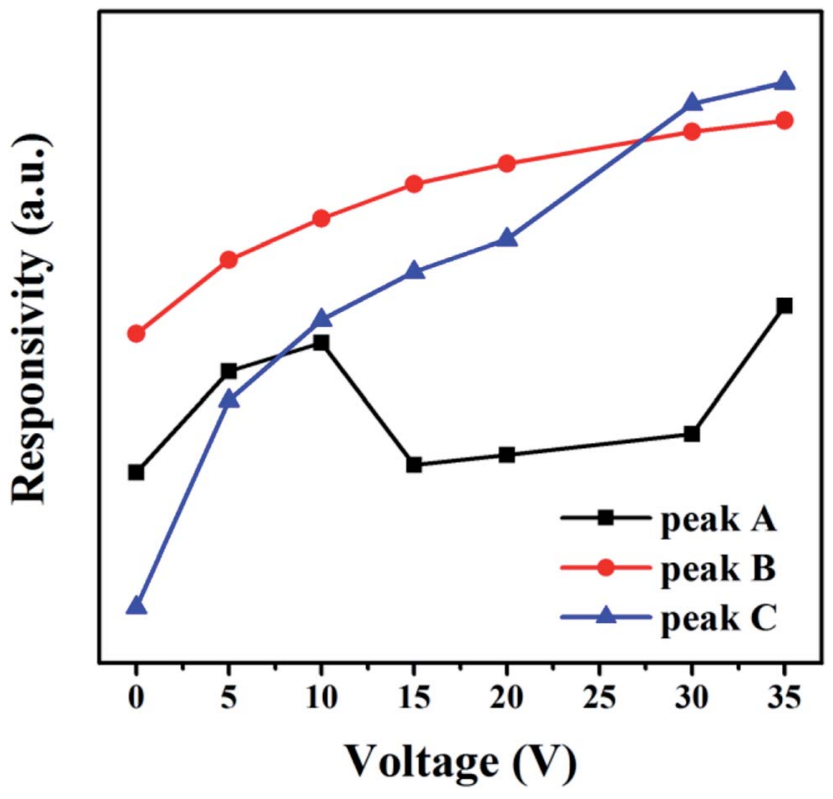

Fig. 4 Intensity of three peaks in the photoresponse spectra at different bias.

illuminated area and $P$ is the light intensity. The relationship between the responsivity and the external quantum efficiency is given by eqn (3): ${ }^{29}$

$$
\eta=\frac{h c R}{e \lambda}
$$

where $h$ is Planck's constant, $c$ is the velocity of light, $e$ is the basic electron charge, and $\lambda$ is the incident light wavelength. The device responses obviously at zero bias, as shown in Fig. 3(b), which demonstrates that the device can be used as a self-powered solar-blind photodetector. A sharp cutoff wavelength defined as the ratio between the maximum and the natural constant $(e \approx 2.718$ ) is located at $256 \mathrm{~nm}$ (close to the bandgap of $\beta-\mathrm{Ga}_{2} \mathrm{O}_{3}$ ), and the predominant peak at $241 \mathrm{~nm}$, both of which have blueshift than the previous report ${ }^{\mathbf{1 9 , 2 0}}$ due to the low defects concentration of the single crystal substrate. The
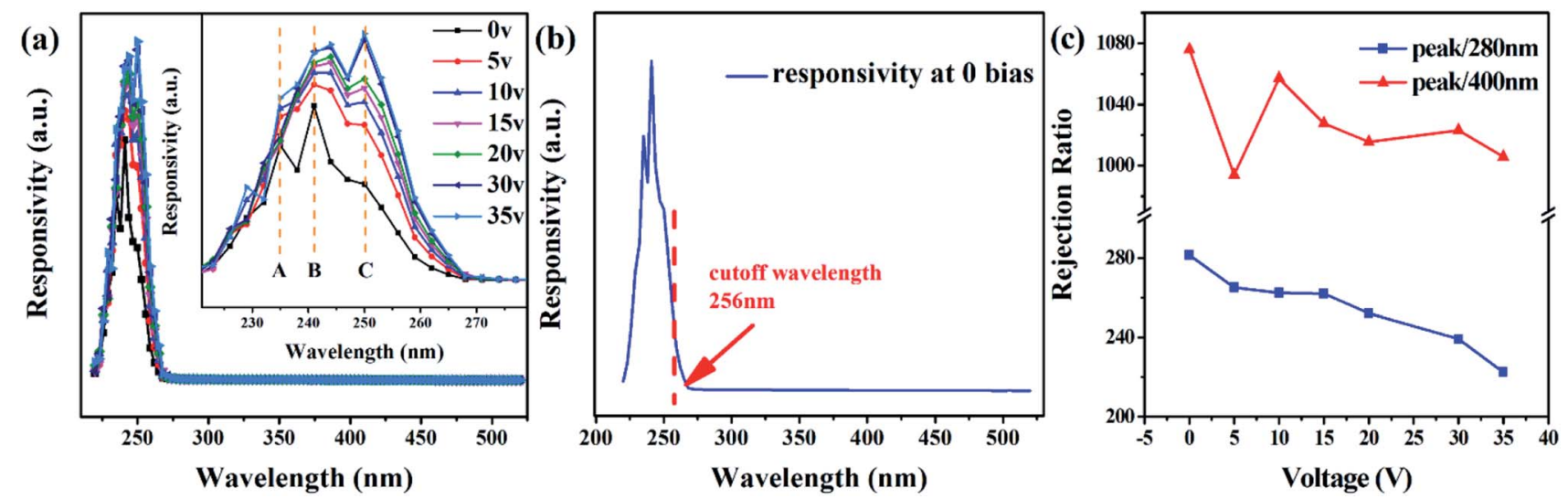

Fig. 3 Photoresponse characteristics for the photodetector: (a) responsivity at different bias, (b) responsivity at 0 bias, (c) solar-blind/visible and solar-blind/UV rejection ratio at different bias. 
solar-blind to visible and UV rejection ratio (defined as the ratio of responsivity at peak to 400 and $280 \mathrm{~nm}$ ) at different reverse bias can reach more than 1000 and 200 respectively, both of which present maximum ratio at zero bias as shown in Fig. 3(c).

The responsivity at solar-blind wavelength range exhibit three peaks, as shown in the inset of Fig. 3(a). All of them changes in different trends as the reverse bias increases, as shown in Fig. 4. This phenomenon can be explained by the different absorption mechanisms of $\mathrm{Ga}_{2} \mathrm{O}_{3}$ to different wavelengths of UV light. According to Medvedeva's calculation, ${ }^{35}$ states of $\mathrm{s}, \mathrm{p}$ and $\mathrm{d}$ of the cations in $\mathrm{Ga}_{2} \mathrm{O}_{3}$ all contributes to the conduction band. Due to the different degree of the orbitals hybridization, the electrons have different velocities on various orbitals. We assume that UV light with different wavelengths excited electrons to different orbitals, which caused different variation trends as the increasing bias. A further investigation will be required to obtain a better understanding of the absorption mechanisms.

\section{Conclusions}

$\mathrm{Cu}$ SBD solar-blind photodetector has been successfully fabricated based on the single crystal $\beta-\mathrm{Ga}_{2} \mathrm{O}_{3}$. The SBD exhibited a higher rectification ratio up to $5 \times 10^{7}$ at $\pm 2 \mathrm{~V}$. The photoresponse spectrum shows a maximum responsivity at $241 \mathrm{~nm}$ and a cutoff wavelength of $256 \mathrm{~nm}$. The low dark current and sharp cutoff wavelength result from the high crystalline quality. The device has a clear response to solar-blind wavelength at zero bias, which confirms it can be used as a self-powered solar-blind photodetector.

\section{Conflicts of interest}

There are no conflicts to declare.

\section{Acknowledgements}

This work was supported by National Natural Science Foundation of China (No. 61574026, 11675198), National Key R\&D Plan (No. 2016YFB0400600, 2016YFB0400601), the Fundamental Research Funds for the Central Universities (No. DUT15LK15, DUT15RC(3)016, DUT16LK29), Liaoning Provincial Natural Science Foundation of China (No. 201602453, 201602176), China Postdoctoral Science Foundation Funded Project (No. 2016M591434).

\section{References}

1 L. Sang, M. Liao and M. Sumiya, Sensors, 2013, 13, 1048210518.

2 M. Razeghi and A. Rogalski, J. Appl. Phys., 1996, 79, 74337473.

3 M. Razeghi, Proc. IEEE, 2002, 90, 1006-1014.

4 E. Monroy, F. Omnès and F. Calle, Semicond. Sci. Technol., 2003, 18, R33.

5 Z. Xu and B. M. Sadler, IEEE Commun. Mag., 2008, 46, 67-73.
6 M.-M. Fan, K.-W. Liu, X. Chen, X. Wang, Z.-Z. Zhang, B.-H. Li and D.-Z. Shen, ACS Appl. Mater. Interfaces, 2015, 7, 2060020606.

7 N. Ueda, H. Hosono, R. Waseda and H. Kawazoe, Appl. Phys. Lett., 1997, 70, 3561-3563.

8 H. Aida, K. Nishiguchi, H. Takeda, N. Aota, K. Sunakawa and Y. Yaguchi, Jpn. J. Appl. Phys., 2008, 47, 8506-8509.

9 Y. Tomm, P. Reiche, D. Klimm and T. Fukuda, J. Cryst. Growth, 2000, 220, 510-514.

10 X. C. Guo, N. H. Hao, D. Y. Guo, Z. P. Wu, Y. H. An, X. L. Chu, L. H. Li, P. G. Li, M. Lei and W. H. Tang, J. Alloys Compd., 2016, 660, 136-140.

11 X. Chen, Y. Xu, D. Zhou, S. Yang, F.-F. Ren, H. Lu, K. Tang, S. Gu, R. Zhang, Y. Zheng and J. Ye, ACS Appl. Mater. Interfaces, 2017, 9, 36997-37005.

12 G. C. Hu, C. X. Shan, N. Zhang, M. M. Jiang, S. P. Wang and D. Z. Shen, Opt. Express, 2015, 23, 13554-13561.

13 D. Guo, H. Liu, P. Li, Z. Wu, S. Wang, C. Cui, C. Li and W. Tang, ACS Appl. Mater. Interfaces, 2017, 9, 1619-1628.

14 Y. Li, T. Tokizono, M. Liao, M. Zhong, Y. Koide, I. Yamada and J.-J. Delaunay, Adv. Funct. Mater., 2010, 20, 3972-3978.

15 B. Zhao, F. Wang, H. Chen, Y. Wang, M. Jiang, X. Fang and D. Zhao, Nano Lett., 2015, 15, 3988-3993.

16 S. Oh, M. A. Mastro, M. J. Tadjer and J. Kim, ECS J. Solid State Sci. Technol., 2017, 6, Q79-Q83.

17 X. Chen, K. W. Liu, Z. Z. Zhang, C. R. Wang, B. H. Li, H. F. Zhao, D. X. Zhao and D. Z. Shen, ACS Appl. Mater. Interfaces, 2016, 8, 4185-4191.

18 B. Zhao, F. Wang, H. Chen, L. Zheng, L. Su, D. Zhao and X. Fang, Adv. Funct. Mater., 2017, 27, 1700264.

19 F. Alema, B. Hertog, O. Ledyaev, D. Volovik, G. Thoma, R. Miller, A. Osinsky, P. Mukhopadhyay, S. Bakhshi, H. Ali and W. V. Schoenfeld, Phys. Status Solidi A, 2017, 214, 1600688.

20 W. Y. Weng, T. J. Hsueh, S. J. Chang, G. J. Huang and H. T. Hsueh, IEEE Photonics Technol. Lett., 2011, 23, 444-446.

21 S. M. Hatch, J. Briscoe and S. Dunn, Adv. Mater., 2013, 25, 867-871.

22 Y. Q. Bie, Z. M. Liao, H. Z. Zhang, G. R. Li, Y. Ye, Y. B. Zhou, J. Xu, Z. X. Qin, L. Dai and D. P. Yu, Adv. Mater., 2011, 23, 649-653.

23 J. J. Hassan, M. A. Mahdi, S. J. Kasim, N. M. Ahmed, H. Abu Hassan and Z. Hassan, Appl. Phys. Lett., 2012, 101, 261108.

24 H. Chen, K. Liu, L. Hu, A. A. Al-Ghamdi and X. Fang, Mater. Today, 2015, 18, 493-502.

25 H. Chen, P. Yu, Z. Zhang, F. Teng, L. Zheng, K. Hu and X. Fang, Small, 2016, 12, 5809-5816.

26 D. Splith, S. Muller, F. Schmidt, H. von Wenckstern, J. J. van Rensburg, W. E. Meyer and M. Grundmann, Phys. Status Solidi A, 2014, 211, 40-47.

27 D. K. Schroder, Semiconductor material and device characterization, John Wiley \& Sons, Hoboken, 3rd edn, 2006.

28 E. H. Rhoderick and R. H. Williams, Metal-semiconductor contacts, Clarendon, Oxford, 2nd edn, 1988.

29 S. M. Sze and K. K. Ng, Physics of semiconductor devices, John Wiley \& sons, Hoboken, 3rd edn, 2006. 
30 K. Sasaki, M. Higashiwaki, A. Kuramata, T. Masui and S. Yamakoshi, IEEE Electron Device Lett., 2013, 34, 493-495.

31 H. He, R. Orlando, M. A. Blanco, R. Pandey, E. Amzallag; I. Baraille and M. Rérat, Phys. Rev. B: Condens. Matter Mater. Phys., 2006, 74, 195123.

32 D. Y. Guo, Z. P. Wu, Y. H. An, X. C. Guo, X. L. Chu, C. L. Sun, L. H. Li, P. G. Li and W. H. Tang, Appl. Phys. Lett., 2014, 105, 023507.
33 Y. H. An, D. Y. Guo, Z. M. Li, Z. P. Wu, Y. S. Zhi, W. Cui, X. L. Zhao, P. G. Li and W. H. Tang, $R S C A d v ., 2016,6$, 66924-66929.

34 W.-Y. Kong, G.-A. Wu, K.-Y. Wang, T.-F. Zhang, Y.-F. Zou, D.-D. Wang and L.-B. Luo, Adv. Mater., 2016, 28, 10725.

35 J. E. Medvedeva and C. L. Hettiarachchi, Phys. Rev. B: Condens. Matter Mater. Phys., 2010, 81, 125116. 